\title{
Fabrication of 3-D Porous Mg/Zn doped Tricalcium Phosphate Bone-Scaffolds via the Fused Deposition Modelling
}

\author{
${ }^{1}$ Samar Jyoti Kalita and ${ }^{2}$ Melissa Ferguson \\ ${ }^{1}$ Department of Mechanical, Materials and Aerospace Engineering, University of Central Florida, Orlando, FL \\ ${ }^{2}$ Department of Agricultural and Biological Engineering, University of Florida, Gainesville, FL
}

\begin{abstract}
Three dimensionally interconnected porous resorbable beta-tricalcium phosphate ( $\beta$-TCP) ceramic scaffolds were developed using the indirect fused deposition modelling process. $\beta$-TCP was doped with $\mathrm{Mg}$ and $\mathrm{Zn}$, separately, to improve its sintering kinetics and facilitate fabrication of viable porous scaffolds. Effects of $\mathrm{Mg}$ and $\mathrm{Zn}$ on sintering kinetics and densification of $\beta$-TCP were studied. Fabricated porous scaffolds were tested for their failure strength under uniaxial compressive loading. Results showed that the scaffolds of Mg doped $\beta$-TCP possessed higher compression strength than the structures of $\mathrm{Zn}$ doped $\beta$-TCP. X-ray powder diffraction technique was used to analyze the phase purity and phase transformation.
\end{abstract}

Key words: Porous Scaffolds, Tricalcium Phosphate, Fused Deposition Modelling, Rapid Prototyping

\section{INTRODUCTION}

Calcium phosphates $(\mathrm{CaPs})$ are preferred materials for bone-graft applications because of their similarity in composition with the bone mineral; excellent bioactivity (ability to develop strong interfacial bonding); ability to promote cellular functions; and osteoconductivity (ability to help in new bone formation). ${ }^{[1]}$ Amongst various phases of $\mathrm{CaPs}$, hydroxyapatite $\left[\mathrm{Ca}_{10}\left(\mathrm{PO}_{4}\right)_{6}(\mathrm{OH})_{2}\right.$, $\left.\mathrm{HA}\right]$ has been studied extensively. However, dense HA has poor rate of biodegradability. On the other hand, tricalcium phosphate $\left[\mathrm{Ca}_{3}\left(\mathrm{PO}_{4}\right)_{2}, \mathrm{TCP}\right]$ is a resorbable phase and exhibits good biocompatibility. Yet, TCP is difficult to sinter, exhibits poor mechanical strength and low resistance to crack-growth propagation. Further, the rate of resorption of TCP is fast and uncontrolled.

Among the three polymorphs of TCP, $\beta$-TCP also known as $\beta$-whitlockite, is a slow-degrading phase ${ }^{[2]}$ and is thus, a promising candidate in bone tissue repair. $\beta$-TCP shows significant biological affinity and activity and hence, responds very well to the physiological environment. ${ }^{[2]}$ Because of these positive characteristics porous $\beta$-TCP is regarded as an ideal bone substitute, which would degrade in vivo with time, allowing bone tissue to grow inside the scaffold. ${ }^{[3,4]}$ It is reported that the resorbability of $\beta$-TCP in vivo might be strongly related to its structure. ${ }^{[5]} \beta$-TCP belongs to $\mathrm{R} 3 \mathrm{CH}$ space group and has a hexagonal crystal structure.

Improving sintering kinetics and properties of $\beta$ TCP is of clinical importance and some research has been done towards this effort. ${ }^{[6-8]}$ However, not much has been achieved in improving its densification and particularly, in fabricating porous scaffolds with 3-D interconnectivity which will slowly degrade in vivo, as the bone cells grow inside.

Integration of sintering additive is a simple way to improve densification and mechanical performance. In this work, we have introduced magnesium $(\mathrm{Mg})$ and zinc $(\mathrm{Zn})$ as sintering additives for $\beta$-TCP. It is also beneficial to integrate these ions in bone-scaffolds, as they are naturally present in bone mineral. By this approach, we improved sintering kinetics and densification of $\beta$-TCP ceramics, and fabricated 3-D porous resorbable ceramic scaffolds as bone-grafts via the indirect fused deposition modelling (FDM) process. The potential advantage offered by porous ceramic implants is the mechanical stability of the highly convoluted interface which develops when bone grows inside the scaffold. It is established that porous bone implants with pore sizes between 100-600 $\mu \mathrm{m}$ are osteoconductive. $^{[9]}$

\section{MATERIALS AND METHODS}

$\beta$-TCP powder (NC/FCC grade) with an average particle size of $3 \mu \mathrm{m}$, was acquired from Rhodia chemicals, Chicago, IL for this research. National Formulary (NF) approved $\beta$-TCP powder, was mixed with small quantities of magnesium oxide ( $\mathrm{MgO}$, Alfa Aesar, Ward Hill, MA, 96\% pure) and zinc oxide ( $\mathrm{ZnO}$, Alfa Aesar, Ward Hill, MA, 99\% pure), separately, using the ball milling technique and then pressed into green pellets, via uniaxial pressing in a steel mold having an internal diameter of $10 \mathrm{~mm}$ at a pressure of 37.5 MPa using a 10-ton press from Carver Inc. Green

Corresponding Author: Samar Jyoti Kalita, Department of Mechanical, Materials and Aerospace Engineering, University of Central Florida, Orlando, FL, P.O. Box 162450 Tel: +1 (407) 823-3159, Fax: +1 (407) 823-0208 
ceramic structures were measured for their geometric bulk density and then sintered in a muffle furnace, at $1250^{\circ} \mathrm{C}$ in air, for $6 \mathrm{~h}$, for densification. A sintering cycle suitable for TCP ceramics was used, based on our previous research ${ }^{[8]}$,to achieve improved densification and to avoid cracks in the sintered specimens.

\section{Processing of 3-D Porous Structures}

Rapid Prototyping (RP) technique has been successfully explored to produce 3 -D porous scaffolds with complex geometry having interconnected porosity. The fused deposition process, commercialized by Stratasys as FDM, is a RP technique where threedimensional (3-D) objects are built layer by layer from a computer-aided design (CAD) file on a computercontrolled fixtureless platform. ${ }^{[10]}$ In this process a thermoplastic polymer filament passes through a heated liquefier, where the liquefier is heated to a temperature that is slightly above the melting point of the build polymer. The liquefier extrudes a continuous bead or road of material through a nozzle and deposits it onto a fixtureless platform. The liquefier movement is computer controlled along the $x$ and $y$ directions, based on the build strategy of the part to be manufactured. For the development of porous $\mathrm{Mg} / \mathrm{Zn}$ doped TCP structures, we have used the indirect fused deposition process in which porous polymeric molds were first fabricated using an FDM with commercially available ABS filaments. The molds were then infiltrated with ceramic slurry followed by binder removal and sintering to produce porous ceramic scaffolds. A process flow chart is shown in Fig.1. Cylindrical polymeric molds were designed and developed using computer aided modelling and fabricated in FDM machine to prepare porous resorbable ceramic scaffolds. We restricted our work to one set of FDM processing parameters i.e., road with, air gap and slice thickness. A detailed description of mold design and processing of porous ceramic structures can be found in reference. ${ }^{[11]}$ FDM processing parameters used to develop molds to fabricate porous ceramic structures with $\sim 30$ vol $\%$ porosity and $\sim 300 \mu \mathrm{m}$ pore size were road with of $0.41 \mathrm{~mm}$, air gap of $1.01 \mathrm{~mm}$ and slice thickness of $0.25 \mathrm{~mm}$.

These controlled porosity molds were infiltrated with ceramic slurry and then sintered to develop cylindrical porous samples of $25 \mathrm{~mm}$ height and $15 \mathrm{~mm}$ diameter. Five samples of each composition were fabricated, sintered and tested in a screw driven uniaxial tensile tester from Instron (Model 3369), to determine mechanical property under uniaxial compressive loading.

Ceramic slurry was prepared by mixing $\mathrm{Mg} / \mathrm{Zn}$ doped $\beta$-TCP powders in water. Powders doped with $1.0 \mathrm{wt} \%$ additive were used to fabricate porous structures, based on densification results. Other additives for the ceramic slurry were Ethanol (Fisher Scientific) as an antifoaming agent and Darvan $821 \mathrm{~A}$ (R.T. Vanderbilt \& Co., Norwalk, CT) as a dispersant. Antifoaming agent and dispersant were added to reduce foaming tendency, maintaining a maximum solids loading in the slurry. The slurry was ball milled for 20 $\mathrm{h}$ in a polyethylene bottle. The binder B-1000 (Rohm and Haas, PA) was added to the mixture just before the infiltration. Porous polymeric molds were then infiltrated with the ceramic slurry. The infiltrated molds were dried at room temperature followed by binder removal and sintering in a muffle furnace.

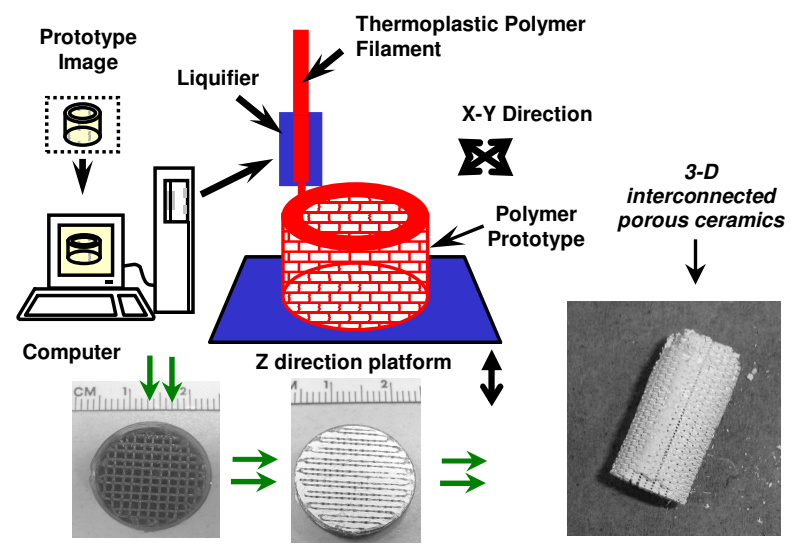

Fig. 1. Schematic of the indirect FDM process

X-ray diffraction (XRD) technique was used to study the effect of sintering additives, temperature and time on phase transformation of $\beta$-TCP. For this, sintered 3-D porous ceramic scaffolds of different compositions were manually crushed and ground to a fine powder, using mortar and pestle. Powder samples of these compositions were placed in the specimen holder of a Rigaku diffractometer, separately, and then analyzed, using Ni-filtered $\mathrm{CuK} \alpha$ radiation $(\lambda=0.1542$ $\mathrm{nm})$ at $40 \mathrm{kV}$ and $40 \mathrm{~mA}$ settings. The XRD patterns were recorded in the $2 \theta$ range of 20 to 45 degrees, with a step size of 0.02 degrees and step duration of $0.5 \mathrm{~s}$.

\section{RESULTS AND DISCUSSION}

Green ceramic pellets prepared via uniaxial pressing were measured for their bulk density prior to pressure-less sintering. Pure-TCP, Mg-TCP and ZnTCP had bulk green density of 1.68, 1.69 and 1.70 $\mathrm{g} / \mathrm{cm}^{3}$, respectively. Small variation in green density was due to manual pressing. Four green specimens of pure and doped TCP (containing 1.0 and $2.5 \mathrm{wt} \% \mathrm{MgO}$ or $\mathrm{ZnO}$ ) were sintered at $1250^{\circ} \mathrm{C}$ to study their effects on densification. Sintered specimens were measured for geometric bulk density and the average of each composition was calculated. Average sintered densities were plotted as a function of composition, shown in Fig. 2. Results showed that sintering at $1250^{\circ} \mathrm{C}$ for $6 \mathrm{~h}$ 
helped in densification of pure and doped $\beta$-TCP. Pure TCP showed sintered density of $3.04 \pm 0.12 \mathrm{~g} / \mathrm{cm}^{3}$, whereas $1.0 \mathrm{wt} \%$ addition of $\mathrm{MgO}$ resulted in the highest density of $3.39 \pm 0.02 \mathrm{~g} / \mathrm{cm}^{3}$ which was $11.5 \%$ increase. Small improvement in densification was achieved with $\mathrm{ZnO}$ addition. Overall, $1.0 \mathrm{wt} \%$ addition showed higher densification than $2.5 \%$. Our results are in line with the work of Georgiou et al. ${ }^{[12]}$, Knowles et $a l .{ }^{[13]}$ and Suchanek et al. ${ }^{[14]}$ where they studied the influence of various on densification and mechanical properties of HA. Ito et al. evaluated the resorbability and solubility of $\mathrm{Zn}$-containing TCP and found that the solubility decreased with increasing $\mathrm{Zn}$ content. ${ }^{[15]}$ They also reported that $\mathrm{Zn}$ has stimulatory effects on bone formation in vitro and in vivo.

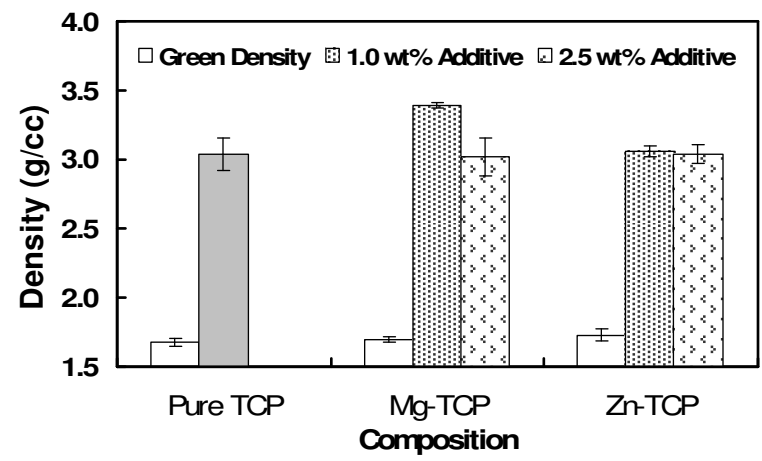

Fig. 2. Densification behaviour of $\beta$-TCP ceramic.

Poor mechanical strength is the biggest drawback of porous ceramic structures for different applications. Porous materials are significantly weaker than their equivalent bulk form. As porosity increases, strength decreases. Cylindrical porous samples of $\beta$-TCP ceramics as fabricated via indirect fused deposition modeling were used to determine their mechanical properties under uniaxial compressive loading. $\beta$-TCP powder doped with $1.0 \mathrm{wt} \%$ of $\mathrm{MgO}$ and $\mathrm{ZnO}$, separately, were used to fabricate 3-D porous ceramic scaffolds, as these compositions showed better sintering behaviour and densification. Porous scaffolds of these compositions fabricated via the indirect FDM process, as shown in Fig. 1, were subjected to mechanical testing; to determine their failure strength under uniaxial compressive loading. Five specimens of each of these compositions were fabricated and tested in a fully automated, screw driven Instron tensile tester at a constant cross-head speed of $0.05 \mathrm{~mm} / \mathrm{min}$. The average compressive strength of each of these compositions was calculated and were found to be 3783 $\mathrm{KPa}$ for $\beta$-TCP doped with $1.0 \mathrm{wt} \%$ of $\mathrm{MgO}$ and 357 $\mathrm{KPa}$ for $\beta$-TCP doped with $1.0 \mathrm{wt} \%$ of $\mathrm{ZnO}$.

The results of compression test were consistent with our densification results, which showed that $\mathrm{Mg}$ is a more effective sintering agent compared to $\mathrm{Zn}$.

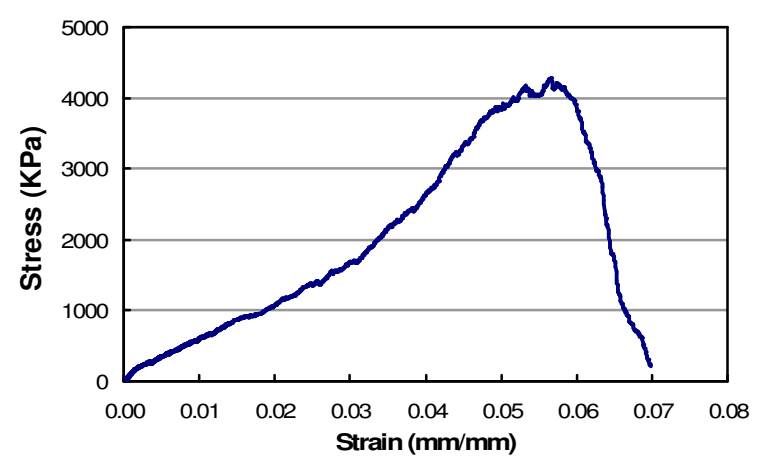

Fig. 3. Typical stress-strain plot of porous Mg-TCP

The results clearly indicate that introduction of $1.0 \mathrm{wt} \%$ of $\mathrm{MgO}$ was more beneficial in improving compression strength of these porous TCP structures than $1.0 \mathrm{wt} \%$ addition of $\mathrm{ZnO}$. We also fabricated porous scaffolds of pure $\beta$-TCP using the same process. However, these structures were weak and their compression strength test did not produce significantly meaningful results. Based on load-displacement data, stress-strain plot was developed for one of the samples containing $1.0 \mathrm{wt} \%$ of $\mathrm{MgO}$ additive and is shown in Fig. 3. Though, we have demonstrated the feasibility of fabricating 3-D porous TCP scaffolds as resorbable bone-grafts, the mechanical strength requires further improvement for possible clinical applications. The failure strength of scaffolds obtained in this research is comparable to the human cancellous bone, which has a typical compressive strength between 0.5-14.6 MPa. ${ }^{[16]}$

To study the effects of sintering additives, temperature and time and the FDM processing variables on phase purity and transformation of $\beta$-TCP ceramics, as-sintered porous scaffolds were crushed and ground into fine powder, using a mortar and pestle. The crushed powder was analyzed in X-ray diffractometer using $\mathrm{CuK} \alpha$ radition. X-ray diffraction patterns of sintered pure $\beta$-TCP and $\beta$-TCP doped with $1.0 \mathrm{wt} . \%$ of $\mathrm{MgO}$ and $\mathrm{ZnO}$, separately, are shown in Fig. 4. Peaks in each X-ray diffraction pattern were recorded and verified using standard JCPDS files, no. 9-169 for $\beta$ TCP and no. 9-348 for $\alpha$-TCP. Almost identical patterns were recorded for all these compositions.

XRD results (Fig. 4) revealed that the presence of 1.0 wt. $\% \mathrm{MgO}$ and $\mathrm{ZnO}$ as additives did not significantly alter the phase purity of $\beta$-TCP. Further, sintering temperature and time did not lead to appreciable phase transformation. However, a few small peaks of $\alpha$-TCP were observed in the XRD patterns, indicating transformation of a small amount of $\beta$-TCP to $\alpha$-polymorph. JCPDS file, no 9-169 used to identify the peaks of beta calcium orthophosphate $(\beta$ TCP, $\left.\beta-\mathrm{Ca}_{3}\left(\mathrm{PO}_{4}\right)_{2}\right)$ showed the presence of all major peaks. JCPDS file, no 9-0348 for orthorhombic calcium phosphate $\left(\alpha-\mathrm{TCP}, \mathrm{Ca}_{3}\left(\mathrm{PO}_{4}\right)_{2}\right)$ was used to identify the 


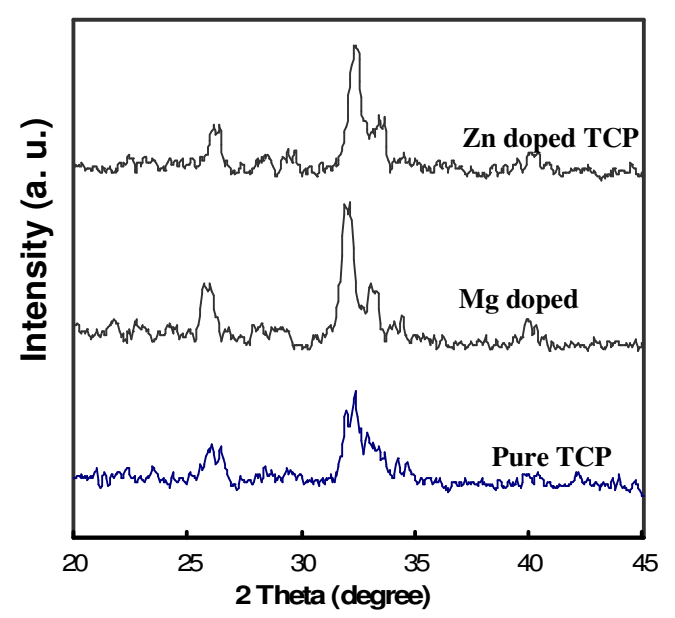

Fig. 4. XRD patterns of pure and doped $\beta$-TCP ceramics after sintering at $1250^{\circ} \mathrm{C}$.

peaks of $\alpha$-TCP. Similar line of results has been reported in literature. Enderle et al. studied the influence of magnesium doping on $\beta$-TCP and found that the transformation temperature of $\beta$-TCP to $\alpha$ phase increased from $1150^{\circ} \mathrm{C}$ without $\mathrm{Mg}^{2+}$ to $1540^{\circ} \mathrm{C}$ with $\mathrm{Mg}^{2+}$ substitution on $\mathrm{Ca}^{2+}$ sites. ${ }^{[17]}$

\section{CONCLUSIONS}

3-D porous resorbable scaffolds of $\mathrm{Mg} / \mathrm{Zn}$ doped $\beta$ TCP ceramic were successfully developed via the indirect FDM technique. $\beta$-TCP was doped with $\mathrm{Mg}$ and $\mathrm{Zn}$ ions to improve its sintering kinetics and densification. Additives improved densification of $\beta$ TCP. $1.0 \mathrm{wt} \%$ addition of $\mathrm{MgO}$ and $\mathrm{ZnO}$ were more effective in improving sintered density of $\beta$-TCP compared to $2.5 \mathrm{wt} \%$ addition. $11.5 \%$ improvement in densification was achieved in $\mathrm{Mg}$ doped $\beta$-TCP structures. Compression test on porous scaffolds showed average failure strength of $3.8 \mathrm{MPa}$ in structures made of Mg doped $\beta$-TCP ceramics. Failure strength of scaffolds of $\mathrm{Zn}$ doped $\beta$-TCP ceramics was fairly low, which conclude that $\mathrm{Mg}$ is more beneficial in improving mechanical behaviour $\beta$-TCP than $\mathrm{Zn}$. XRD results revealed that the presence of these additives did not significantly alter the phase purity of $\beta$-TCP. Sintering and FDM processing parameters did not lead to appreciable phase transformation, as well.

\section{REFERENCES}

1. Hench, L.L., 1998. Bioceramics. J. Am. Ceram. Soc., 81: 1705-28.

2. Kivrak, N. and A.C. Tas, 1998. Synthesis of hydroxyapatite (HA) / tricalcium phosphate and their sintering behavior. J. Am. Ceram. Soc., 81: 2245-52.
3. Jarcho, M., J.F. Kay, K.I. Gumaer, R.H. Doremus, and H.P. Drobeck, 1977. Tissue, cellular and subcellular events at a bone-ceramic hydroxylapatite interface. J Bioeng, 1: 79-92.

4. Varma, H.K., S.N. Kalkura, and R. Sivakumar, 1998. Polymeric precursor route for preparation of calcium phosphate compounds. Ceram. International, 24: 467-70.

5. Okazaki, M. and M. Sato, 1990. Computer graphics of hydroxyapatite and beta-tricalcium phosphate. Biomaterials, 11: 573-8.

6. Ryu, H.S., H.J. Youn, K.S. Hong, B.S. Chang, C.K. Lee, and S.S. Chung, 2002. An improvement in sintering property of b-tricalcium phosphate by addition of calcium pyrophosphate. Biomaterials, 23: 909-14.

7. Wong, L.H., B. Tio, and X. Miao, 2002.

Functionally graded tricalcium phosphate/fluoroapatite composites. Materials Science and Engineering C, 20: 111-115.

8. Kalita, S.J., H. Bhatt, and A. Dhamne, 2006. MgO$\mathrm{Na}_{2} \mathrm{O}-\mathrm{P}_{2} \mathrm{O}_{5}$-based Sintering Additives for Tricalcium Phosphate Bioceramics. J Am Ceram Soc, 89: 875-81.

9. Hulbert, S.F., S.J. Morrison, and J.J. Klawitter, 1972. Tissue Reaction to Three Ceramics of Porous and Non-Porous Structures. J. Biomed. Mater. Res., 6: 347-374.

10. Walters, W.A. 1992."Rapid Prototyping Using FDM: A Fast, Precise, Safe Technology". in Solid Freeform Fabrication Proceedings.

11. Bose, S., S. Sugiura, and A. Bandyopadhyay, 1999. Processing of controlled porosity ceramic structures via Fused Deposition Process. Scripta Materialia, 41: 1009-14.

12. Georgiou, G. and J.C. Knowles, 2001. Glass reinforced hydroxyapatite for hard tissue surgery-part 1: Mechanical properties. Biomaterials, 22: 2811-5.

13. Knowles, J.C., S. Talal, and J.D. Santos, 1996. Sintering effects in a glass reinforced hydroxyapatite. Biomaterials, 17: 1437-42.

14. Suchanek, W., M. Yashima, and M. Yoshimura, 1997. Hydroxyapatite ceramics with selected sintering additives. Biomaterials, 18: 923-33.

15. Ito, A., H. Kawamura, S. Miyakawa, P. Layrolle, N. Kanzaki, G. Treboux, K. Onuma, and S. Tsutsumi, 2002. Resorbability and solubility of zinc-containing tricalcium phosphate. J Biomed Mater Res, 60: 224-31.

16. Goulet, R.W., S.A. Goldstein, M.J. Ciarelli, J.L. Kuhn, M.B. Brown, and L.A. Feldkamp, 1994. J. Biomechanics, 27: 375.

17. Enderle, R., F. Gotz-Neunhoeffer, M. Gobbels, F.A. Muller, and P. Greil, 2005. Infuence of magnesium doping on the phase transformation temperature of Beta-TCP ceramics examined by Rietveld refinement. Biomaterials, 26: 3379-84. 